Hypothyroxinaemia, which is common in the preterm infant, and thyrotoxicosis, which is rare, are important neonatal thyroid disorders. Their causes and treatment are discussed.

Correspondence to: Dr Ogilvy-Stuart, Rosie Hospital, Addenbrooke's NHS Trust, Cambridge CB2 2SW, UK amanda.ogilvy-stuart@ addenbrookes.nhs.uk

Accepted 14 May 2002
T hyroid hormones are important for energy metabolism, the metabolism of nutrients and inorganic ions, thermogenesis, and for stimulation of growth and development of various tissues at critical periods including the central nervous system and skeleton. A number of tissue and cell functions are modified by varying patterns of genomic activation and protein and receptor synthesis, which accounts for the many variable actions. Thyroid hormones potentiate the actions of catecholamines (the effects of which are prominent in the hyperthyroid state), and their effect on somatic and skeletal growth are in part mediated by stimulation of the synthesis and action of growth hormone and insulin-like growth factor.

In this review, I will discuss the ontogeny of thyroid function, thyroid function in preterm infants, and the use of thyroid hormones in these babies. I will review neonatal thyrotoxicosis and, finally, give suggestions for the investigation of babies born to mothers with thyroid disease.

\section{DEVELOPMENT OF THYROID FUNCTION}

During fetal life, the thyroid gland develops with production of thyroxine (T4) and triiodothyronine (T3) and secretion into the serum from about 12 weeks gestation, the levels of which increase to term. Throughout gestation, maternal $\mathrm{T} 4$ crosses the placenta in limited amounts, but in the first trimester, this plays a critical role in central nervous system development, as exemplified by the fetal neurological impairment seen in fetomaternal Pit-1 deficiency ${ }^{1}$ and severe iodine deficiency. ${ }^{2}$ In both situations there is severe maternal and fetal hypothyroidism. In areas of endemic iodine deficiency, iodine supplementation to women before pregnancy or up to the end of the second trimester protects the fetal brain from the effects of iodine deficiency whereas third trimester or neonatal supplementation does not improve neurological outcome. ${ }^{2}$

From the second trimester, the continued transfer of T4 from mother to fetus remains important for those babies with primary thyroid abnormalities, as despite cord blood levels only reaching about $40 \%$ of normal in those with a total inability to synthesise $\mathrm{T} 4,{ }^{3}$ neurological development is near normal if replacement is started promptly. From mid-gestation, hypothalamic expression of thyrotrophin releasing hormone (TRH), pituitary production of thyroid stimulating hormone (TSH), and thyroidal production of T4 rise steadily until 36 weeks gestation. Even when the fetal thyroid gland becomes autonomous, normal thyroid function in the mother may be important for normal neurological development. ${ }^{4}$

The bioactivity of thyroid hormone is regulated by enzymic deiodination in peripheral tissues. T4 is converted by outer ring deiodination into T3, which has three to four times the metabolic potency of T4. Both T4 and T3 are inactivated by inner ring deiodination to reverse T3 (rT3) and 3,3'-diiodothyronine respectively. Three iodothyronines are involved in this process. Type I deiodinase (Dl) has both inner and outer ring deiodination activity. It is located in the liver, kidney, and the thyroid and is important for T3 production. Type II deiodinase (D2) catalyses only outer ring deiodination and is found in the brain, pituitary, and brown adipose tissue. It is important for local T3 production within these tissues. Type III deiodinase (D3) has only inner ring activity and is present in brain, skin, and intestine. $^{5}$

T3 and T4 are also inactivated to sulphated analogues by sulphotransferase in fetal liver. ${ }^{6}$ Sulphated iodothyronines are major thyroid hormone metabolites in the fetus, ${ }^{78}$ and sulphate conjugation of the iodothyronines accelerates deiodination. ${ }^{910}$

In the fetus, levels of $\mathrm{T} 3$ are low, and increase only at the end of gestation. In contrast, rT3 levels are high, only decreasing in late gestation and into the neonatal period. Hence endogenous thermogenesis is minimised and anabolism is promoted. High D3 activity in the placenta (converting a large proportion of T4 and T3 into rT3 and 3,3'-diiodothyronine during placental transfer), and in both fetal liver and the liver of preterm babies contribute to the high rT3 levels. ${ }^{5}$ Both D1 and D2 are present from the third trimester-the increase in Dl activity mirrored by a rise in $\mathrm{T} 3$ from 30 weeks gestation. ${ }^{7}$ Fetal tissues that are dependent on T3 (particularly the brain) rely on local T4 into T3 conversion via D2. ${ }^{11}$

\section{THYROID FUNCTION IN THE PRETERM BABY}

In the preterm baby, and fetus of similar gestation, the thyroid axis is immature, with reduced hypothalamic TRH production and secretion, an immature response of the thyroid gland to TSH, an inefficient capacity of the follicular cell

Abbreviations: T4, thyroxine; T3, triiodothyronine; $\mathrm{TRH}$, thyrotrophin releasing hormone; $\mathrm{TSH}$, thyroid stimulating hormone; TSI, thyroid stimulating immunoglobulin; PTU, propylthiouracil 
of the thyroid to organify iodine, and a low capacity to convert T4 into active T3. Hence, when a baby is born preterm, the level of T4 is lower than that of term babies and correlates with gestational age and birth weight. ${ }^{12}$ Levels of TSH and T3 are normal to low, free T4 concentrations are also low, and thyroglobulin levels are high (reflecting increased thyroid gland production of poorly iodinated thyroid hormone precursor). Responses of TSH and T4 to TRH are normal, reflecting that the site of immaturity is the hypothalamus. In addition, hypothyroxinaemia is in part secondary to reduced levels of thyroid binding globulin. These data would suggest that the hypothyroxinaemia of prematurity is physiological.

Normally at delivery at term, with the fall in ambient temperature, there is a surge in TSH to about $80 \mathrm{mU} / \mathrm{ml}$ within about 30 minutes. This stimulates the thyroid gland to release T4 and T3, which rise to well above normal levels. In term babies, the total and free T4 levels fall over the next four to six weeks, but are still higher than in older children and adults at six months. T3 levels gradually reach infancy levels between 2 and 12 weeks of age.

In the preterm infant, there is a similar TSH, T4, and T3 surge, but the magnitude is attenuated. In babies born at more than 30 weeks gestation, T4 and free T4 levels increase over the next six to eight weeks to levels comparable to those of babies born at term. ${ }^{13-15}$ However, in the preterm baby born at less than 30 weeks gestation and with very low birth weight $(<1500 \mathrm{~g})$, the TSH and T4 surges are limited and there is often a fall in T4 in the first one to two weeks after birth, and transient hypothyroxinaemia is common. ${ }^{15-18}$ The more preterm the baby the more pronounced is this hypothyroxinaemia. Although there is an increase in the incidence of transient primary hypothyroidism in these babies (when the TSH level is also raised) ${ }_{,}^{17}$ in the majority, the hypothyroxinaemia is associated with a normal TSH level. ${ }^{19}$ The severity of the neonatal illness is also reflected in the T4 levels, with infants who require ventilatory assistance for respiratory distress syndrome having the lower $\mathrm{T} 4$ levels, ${ }^{20}$ possibly suggesting non-thyroidal illness (sick euthyroid syndrome), which may be an adaptive response to illness resulting in a depressed metabolic rate.

The reason for this hypothyroxinaemia is multifactorial, including the loss of the maternal T4 contribution, immaturity of the hypothalamic-pituitary axis, the responsiveness of the thyroid gland to TSH, and immaturity of peripheral tissue deiodination. Iodine balance is negative in the first few weeks after birth in these very low birthweight babies, suggesting an inability to augment thyroidal iodine uptake and increase T4 secretion. ${ }^{15}$ These changes are further compounded by iodine deficiency in areas of the world with low environmental iodine, and by the use of iodine-containing antiseptics, drugs, and contrast agents. ${ }^{21}$ The relatively low T3 levels are not increased by T4 administration, probably because of low Dl levels in the liver-most of the circulating T3 coming from thyroidal production. ${ }^{22}$

\section{DOES THIS HYPOTHYROXINAEMIA MATTER?}

In preterm infants, almost all reports document an association between adverse outcome and hypothyroxinaemia. Severe hypothyroxinaemia, as measured on blood spots in newborn screening programmes that utilise T4 (rather than TSH, which is used in the United Kingdom), has been associated with an increase in perinatal mortality and morbidity, with prolonged oxygen supplementation, mechanical ventilation, and hospital stay, $^{23}$ an increased incidence of intraventricular haemorrhage, ${ }^{24}$ and a greater risk of echolucencies in cerebral white matter on ultrasonography. ${ }^{25}$ In the survivors, an increased risk of neurodevelopmental problems, reduced intelligence quotient (IQ), ${ }^{26-28}$ and disabling cerebral palsy ${ }^{26}$ has been reported, even when corrected for potential confounders including gestation, fetal growth, and illness severity. A British cohort in which T3 was measured twice in the first week and weekly thereafter in babies of less than $1850 \mathrm{~g}$ has shown an association between a T3 level less than $0.3 \mathrm{nmol} / \mathrm{l}$ and a reduction on the Bayley mental developmental index score, and the Bayley psychomotor index score of 8.3 points and 7.4 points respectively at 18 months, even with adjustment for confounding variables known to affect outcome. ${ }^{29}$ When reassessed between 7.5 and 8 years, overall IQ was 6.6 points lower in those whose lowest T3 had been $<0.3 \mathrm{nmol} / \mathrm{l}^{30}$

\section{SHOULD PRETERM BABIES BE SUPPLEMENTED WITH THYROID HORMONES?}

It is unclear whether this association between low T3 or low T4 and short term morbidity, mortality, and long term disability is causal or merely a reflection of illness severity in the most premature babies. However, this has resulted in a number of studies of thyroid hormone supplementation in an attempt to reduce these problems. The numbers in each study are small and the use of different doses at different times and different thyroid hormones (T4 or T3) precludes a meta-analysis. Of the eight published studies, four were randomised or quasirandomised controlled trials and have been summarised in a Cochrane review. ${ }^{31}$ In the first of these studies, Chowdrey et $a l^{32}$ compared treatment with thyroxine with treatment with placebo in babies of 25-28 weeks gestation with hypothyroxinaemia (T4 $<4 \mu \mathrm{g} / \mathrm{dl}$ and TSH $<20 \mathrm{IU} / \mathrm{l}$ on two occasions). There was no effect of thyroid supplementation on linear growth, weight gain, head circumference at 10 months, or psychomotor development at 12 and 24 months, and no difference in mortality. Apart from small numbers ( 11 treated $v 12$ placebo), it should be noted that T4 treatment was not started until T4 levels were at their lowest ( 2 weeks), and T4 treatment did not increase T4 levels. In addition, there was evidence of long term psychomotor disability in the T4 treated patients with developmental scores of approximately 85 .

Amato et $\mathrm{l}^{33}$ studied babies of less than 32 weeks gestation, requiring more than $40 \%$ supplemental oxygen. Treatment with T4 $(50 \mu \mathrm{g} / \mathrm{kg} /$ day in two doses intravenously), started on the first day of life for two days, was compared with no treatment. Mortality (38\%) was the same in both groups, although there was a lowered $\mathrm{FIO}_{2}$ in the first 72 hours and there was no long term effect on any other respiratory outcome. Neurodevelopment was not assessed.

Vanhole $e t a^{34}$ undertook a double blind, placebo controlled study of T4 treatment ( $20 \mu \mathrm{g} / \mathrm{kg} /$ day from day l for two weeks) for babies born at 25-30 weeks gestation. There was no effect on mortality, respiratory complications including chronic lung disease, intraventricular haemorrhage, retinopathy of prematurity, or growth. There was no difference in the Bayley mental development index or Bayley psychomotor developmental index at 7 months corrected age.

Van Wassenaer et $a l^{35}$ also conducted a double blind, placebo controlled study of T4 ( $8 \mu \mathrm{g} / \mathrm{kg} /$ day for six weeks) in babies of 25-29 weeks gestation. Whereas the T4 levels in the placebo group fell by day 7 , they rose in the treatment group in the first 3 days with no nadir at 7 days. Although T4 levels remained raised, they were lowest in babies of 25 and 26 weeks gestation. Both thyrotrophin and T3 levels were suppressed during T3 treatment. On discontinuation of T4 at 6 weeks of age, T4 levels fell and were below cord blood levels at 56 days in babies born at 25 and 26 weeks gestation. There was no significant difference in mortality, severity of respiratory disease, intraventricular haemorrhage, or periventricular leucomalacia. There was no significant difference in Bayley mental development index or psychomotor developmental index performed at 6, 12, and 24 months of age. However, in a posteriori subgroup analysis by gestational age at 24 months, there was a significant difference in the Bayley mental development index ( 18 points higher) in the T4 treated group born at 25-26 
Table 1 Babies at high risk of neonatal thyrotoxicosis

Mother

Raised thyroid binding immunoglobulin levels in pregnancy

Thyroid binding immunoglobulin level not assessed

Clinical thyrotoxicosis in third trimester

Thionamide required in third trimester

Family history of TSH receptor mutation

Baby

Evidence of fetal thyrotoxicosis

weeks gestation compared with the placebo group, but a significantly lower mental development index (10 points) in T4 treated infants of 27-29 weeks gestation.

Although there are obvious pitfalls in posteriori analysis, this study does pose a number of questions that require clarification. The data suggest that the nadir in thyroid hormones seen at 7 days in the extremely preterm baby may be detrimental to brain development but has little effect on respiratory function or growth. There was no assessment of thyroid function before T4 was started, so it is possible that some babies had underlying thyroid or hypothalamic-pituitary dysfunction.

Also of concern is the suggestion that supplemental T4 may be detrimental to babies born after 26 weeks gestation. These data are supported by an ACTOBAT (Australian collaborative trial of antenatal thyrotropin-releasing hormone) trial in which $200 \mu \mathrm{g}$ TRH was administered in addition to corticosteroids to women at risk of preterm delivery to ascertain the efficacy in reducing neonatal respiratory distress. Treatment with TRH was associated with consistent deficits in major milestones at 12 months, particularly motor delay, social delay, and sensory impairment. ${ }^{36}$

Thus, although severe hypothyroxinaemia is associated with neonatal morbidity and developmental disability, it is unclear whether in those with normal thyrotropin levels (and no abnormalities of the hypothalamic-pituitary axis) this is an association (usually in the sickest infants) or the cause. The data to date do not support supplementation with thyroid hormones in these babies, and indeed it may be detrimental to long term neurological outcome. The possible advantage to those babies born at 25 and 26 weeks gestation requires further clarification before recommendation of thyroid hormone supplementation. These conclusions are supported by a recent American review. ${ }^{37}$

\section{NEONATAL THYROTOXICOSIS}

Although rare, this condition is associated with a high mortality and needs to be anticipated so that, if necessary, treatment can be instigated promptly.

The cause of hyperthyroidism in the newborn is usually transplacental passage of thyroid stimulating immunoglobulins (TSIs) from mothers with Graves' disease, or, more rarely, Hashimoto's thyroiditis. ${ }^{38}$ TSIs may continue to be produced even after ablation of the thyroid gland with surgery or radioiodine. Neonatal thyrotoxicosis secondary to TSIs is a transient disorder, limited by the clearance of maternal antibody from the baby's circulation. In contrast, a rarer form of persistent hyperthyroidism, which is usually dominantly inherited, can occur in the absence of maternal autoimmunity because of activating mutations in the TSH receptor ${ }^{39} 40$ and activating mutations of the stimulatory G protein in McCuneAlbright syndrome. ${ }^{41} 42$ Activating mutations of the TSH receptor should be suspected if there are more than two generations affected with thyrotoxicosis, or there are other first degree relatives with thyrotoxicosis, as the condition may be easily missed.
Neonatal hyperthyroidism is rare. The prevalence of Graves' disease in pregnant women is approximately $0.2 \% .^{43}{ }^{44}$ Although it is usually stated that only $1-1.5 \%$ of their offspring will have overt hyperthyroidism, ${ }^{45}$ this figure may be much higher: $5 \%,{ }^{46} 8 \%,{ }^{47} 10 \%,{ }^{48}$ and $12.5 \%{ }^{49}$ have been quoted. Thus there will be one case of overt neonatal thyrotoxicosis for every 4000-50 000 deliveries, with a further 3\% of babies of mothers with Graves' disease having biochemical thyrotoxicosis in the absence of symptoms. ${ }^{46}$ The incidence of hyperthyroidism in babies of mothers who require treatment with antithyroid drugs to term may be as high as $22 \%{ }^{47}$

The mortality has been reported to be $12-20 \%,{ }^{50}{ }^{51}$ usually from heart failure, but other complications include tracheal compression, infections, and thrombocytopenia.

\section{CLINICAL FEATURES}

Fetal outcome is related to the control of maternal thyrotoxicosis, with complications being considerably increased in mothers who remain hyperthyroid in the second half of pregnancy. ${ }^{52}$ The hyperthyroid fetus is often growth retarded, both from a direct effect of hyperthyroidism and associated pre-eclampsia. ${ }^{53}$ Tachycardia is common and often used to diagnose fetal thyrotoxicosis. Non-immune hydrops has been described, presumably secondary to cardiac failure. ${ }^{54}$ Goitre may be apparent on ultrasound scanning.

There is an increased incidence of intrauterine death which has been reported to occur in $5-7 \%$ of offspring of mothers receiving medical or surgical treatment for thyrotoxicosis and in $24 \%$ of offspring of untreated, hyperthyroid mothers. ${ }^{55}$ Preterm delivery occurs in $4-11 \%$ of mothers treated for thyrotoxicosis during pregnancy and in 53\% of mothers who remain untreated. ${ }^{55}$

In the neonate, symptoms and signs of thyrotoxicosis may be apparent at birth or may be delayed for several days, because of either the effect of maternal antithyroid drugs or the effect of coexistent blocking antibodies, ${ }^{56}{ }^{57}$ but are usually apparent by 10 days of life. ${ }^{58}$ However, overt thyrotoxicosis has been reported to occur as late as 45 days after birth. ${ }^{56}$ Levels of TSH binding inhibitor immunoglobulin and TSH immunoglobulin levels from mothers during the third trimester and from the infant in the neonatal period correlate well with the development of neonatal hyperthyroidism. ${ }^{4659} 60$

Most infants have a goitre. Central nervous system signs include irritability, jitteriness, and restlessness. Eye signs such as periorbital oedema, lid retraction, and exophthalmos may be present even in the absence of maternal eye signs. Exophthalmos can occur even in thyrotoxicosis secondary to causes other than maternal Graves' disease. ${ }^{40}$ Cardiovascular signs include tachycardia and arrhythmias, but may progress to cardiac failure. Systemic and pulmonary hypertension may be present. Signs of hypermetabolism include voracious appetite, weight loss, diarrhoea, sweating, and flushing. Other signs include persisting acrocyanosis, hepatosplenomegaly, lymphadenopathy, thymic enlargement, bruising and petechiae secondary to thrombocytopenia, and hyperviscosity. Advanced bone age, craniosynostosis, and microcephaly may be evident in both the fetus and newborn.

The duration of neonatal thyrotoxicosis secondary to maternal Graves' disease is determined by the persistence of transplacentally acquired maternal TSIs and usually remits after 8-20 weeks. $^{59}$ Virtually all infants are euthyroid by 48 weeks postnatal age. ${ }^{61}$ Rarely the thyrotoxicosis persists, possibly because of endogenous TSI production, and these children may require ablative thyroid treatment. ${ }^{51}$ Patients with apparent persistent neonatal Graves' disease often have an autosomal dominant pattern of inheritance, which is also observed in families with activating mutations in the TSH receptor. ${ }^{39}$ Some families thought to have persistent neonatal Graves' disease may therefore have TSH receptor mutations. 
Transient neonatal hypothyroidism may occur in babies of mothers with a current or past history of Graves' disease. This may be due to transplacental passage of thionamides, but apparent transient "athyrosis" has been documented secondary to the blocking nature of some thyrotrophin binding inhibitory immunoglobulins. ${ }^{62}$ Interestingly, some babies may develop transient hypothyroxinaemia, with a picture of central hypothyroidism. ${ }^{63}{ }^{64}$ The mechanism for this may be suppression of the fetal (and then neonatal) thyroid axis by excessive T4 from either the thyrotoxic mother or thyrotoxic baby (secondary to transplacental passage of TSI). ${ }^{65}$

\section{LONG TERM EFFECTS}

Although there is a report of an increase in congenital anomalies in babies of mothers who were hyperthyroid at the time of embryogenesis, ${ }^{66}$ this has not been confirmed. ${ }^{67}{ }^{68}$ There is generally no increase in congenital anomalies in babies of mothers receiving antithyroid drugs. ${ }^{67}$ Carbimazole is rapidly converted in the liver into methimazole ${ }^{69}$ which is the preparation available in the United States. The latter has been linked to the development of cutis aplasia in the offspring of mothers treated with thionamides in pregnancy, ${ }^{70-72}$ although several large series studies have not confirmed this observation. ${ }^{668}$ Of greater concern is that the fetus of a mother on thionamides may be rendered hypothyroid; however, there is no evidence of adverse effects, particularly intellectual and growth defects in children exposed to antithyroid drugs in utero compared with both siblings who were not exposed or age matched controls. ${ }^{73-76}$

There are few data on long term outcome of babies who had neonatal thyrotoxicosis. ${ }^{5177}$ Daneman and Howard ${ }^{77}$ found craniosynostosis in six of eight children who had skull radiographs, and four of six children over 2 years of age who underwent assessment of intellectual function had varying degrees of impairment-all had craniosynostosis. One of three below two years had significant psychomotor retardation and synostosis. Physical growth was normal in all children, in contrast with the findings of Hollingsworth and Mabry, ${ }^{51}$ who reported poor growth in three of four patients and psychological impairment in all four. The patients assessed by Hollingsworth and Mabry possibly had a gene mutation in the TSH receptor, as all had an autosomal dominant history of thyrotoxicosis.

\section{MANAGEMENT OF BABIES AT RISK OF NEONATAL THYROTOXICOSIS}

Figure 1 shows a suggested scheme for the management of a baby at risk of neonatal thyrotoxicosis. This will include all babies of mothers with a current or past history of Graves' disease (including those who have had ablative treatment with surgery or radioiodine), and those rare families with a family history of neonatal thyrotoxicosis secondary to TSH receptor mutations. The diagnosis of euthyroid, hypothyroid, or hyperthyroid has to be made in the light of expected TSH and T4 levels for postnatal age, as the huge surge in both after delivery will necessarily mean that the usual normal ranges for adults and older children are inappropriate.

Babies at high risk of thyrotoxicosis (table 1) - that is, those who have had evidence of thyrotoxicosis in utero, those whose mothers are receiving antithyroid treatment at the time of delivery, and those whose mothers have high titres of TSI, or there was evidence of fetal hyperthyroidism-may require close observation in hospital for the first few days after delivery. Although levels of maternal TSI that are five times the upper limit of normal are associated with fetal and neonatal thyrotoxicosis, ${ }^{60}$ much lower levels may also result in fetal and neonatal thyrotoxicosis. ${ }^{68}$

For babies at lower risk-for example, those whose mothers have normal TSI levels_-follow up may be more relaxed and the babies discharged immediately after delivery. In all cases, parents should be advised on the symptoms of thyrotoxicosis and the general practitioner should be informed.

\section{BREAST FEEDING}

Both propylthiouracil (PTU) and methimazole (from carbimazole) are detected in breast milk but appear not to affect neonatal thyroid function if the mother's dose of carbimazole is less than $15 \mathrm{mg}$ a day and of PTU is less than $150 \mathrm{mg}$ a day. ${ }^{78-80}$ PTU, which is highly protein bound, is excreted into the milk in much lower concentrations $(0.025-0.077 \%)$ than methimazole, which has a serum to milk ratio of $1 .{ }^{81} 82$ Therefore, for mothers on thionamides wishing to breast feed, PTU would be preferable, but carbimazole is not contraindicated.

\section{TREATMENT OF NEONATAL THYROTOXICOSIS}

It is unclear whether biochemical thyrotoxicosis in the absence of clinical symptoms and signs should be treated. Although there are few data, my own feeling is that the long term outcome of babies with neonatal thyrotoxicosis is of concern, so I would recommend that all but the mildest biochemical hyperthyroidism should be treated. It is probable, however, that the effects on the developing brain and skeleton have been initiated in utero. Induced hypothyroidism secondary to treatment may be just as detrimental and needs to be closely monitored.

Medical treatment follows the same principals as treatment of older subjects. Thionamides (PTU and carbimazole) act by blocking the organification of iodine and the coupling of iodothyronine residues - that is, blocking thyroid hormone synthesis. In addition, PTU inhibits the peripheral deiodination of T4 to more active T3 and may therefore be the preferred drug. ${ }^{83}$

The thyrotoxic newborn may be treated with either 5-10 $\mathrm{mg} / \mathrm{kg} /$ day PTU in three divided doses or $0.5-1.5 \mathrm{mg} \mathrm{kg} / \mathrm{day}$ carbimazole as a single daily dose. As the drugs block the synthesis but not the release of thyroid hormones, a clinical response to thionamides may not occur until the thyroid hormone stored in the colloid is depleted. Therefore iodine solution, which suppresses thyroid hormone synthesis and has a prompt effect in inhibiting the release of thyroid hormones, may be used in conjunction. Saturated KI (48 mg iodine per drop) may be given in a dose of 1 drop daily, or Lugol's solution ( $5 \% \mathrm{KI}$; about $8 \mathrm{mg}$ iodine/drop) may be given in a dose of 1 to 3 drops daily. By virtue of their iodine content inhibiting thyroid secretion and their ability to inhibit extrathyroidal conversion of T4 into T3, iopanoic acid and sodium ipodate have also been used successfully in the treatment of neonatal thyrotoxicosis. ${ }^{84}{ }^{85}$ The stated dose is $0.5 \mathrm{~g}$ every three days.

$\beta$-Blockers are effective in controlling symptoms caused by adrenergic stimulation. In addition, they inhibit deiodination of T4 to T3. Propranolol may be used in a dose of 0.27-0.75 $\mathrm{mg} / \mathrm{kg} 8$ hourly. However, it can cause serious hypoglycaemia, bradycardia, and hypotension, so babies require close monitoring. Specific treatment for cardiac failure may be required, for example with digoxin and diuretics.

Severely thyrotoxic babies may be treated with prednisolone, which suppresses deiodination of T4 to T3 and compensates for hypercatabolism of endogenous glucocorticoids induced by T3 and T4. The dose of prednisolone is $2 \mathrm{mg} / \mathrm{kg} /$ day.

Sedatives may also be helpful in managing irritability and restlessness.

Exchange transfusion has been used in an attempt to reduce TSI levels (or incidentally to treat haemolytic disease of the newborn), with some reduction in antibody levels but failing to prevent neonatal thyrotoxicosis. ${ }^{86-88}$

If a baby requires treatment for thyrotoxicosis, it should be reviewed approximately weekly until stable, then every one to two weeks, and drug doses reduced when possible. Treatment 


\section{(1) Maternal hypothyroidism}

This is usually secondary to Hashimoto's thyroiditis and the mother may be producing thyroid inhibiting or rarely thyroid stimulating antibodies so the baby may develop transient hypothyroidism or, very rarely, hyperthyroidism. These babies should be reviewed at 10 days to 2 weeks and thyroid function taken (TSH and fT4).

If the maternal hypothyroidism is secondary to congenital aplasia or hypoplasia of the thyroid gland, there is only a slightly increased risk to the baby of hypothyroidism and Guthrie should suffice.

If the hypothyroidism is secondary to treatment (surgery or radioiodine) for Graves' disease, the baby is at risk of neonatal thyrotoxicosis and will need to be managed as below.

\section{(2) Maternal thyrotoxicosis}

Babies at risk for congenital hyperthyroidism

(Maternal Graves' disease, family history of activating mutations in TSH receptor)

for $\mathrm{FT} 4, \mathrm{TSH}, \mathrm{TSI}$ (if available) concentration + examination

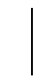

If high risk (table 1) repeat fT4, TSH + examination

Age 2-7 days:

In all babies, repeat fT4, TSH and examination

Age 10-14 days

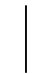

Results of thyroid function from any of the above:

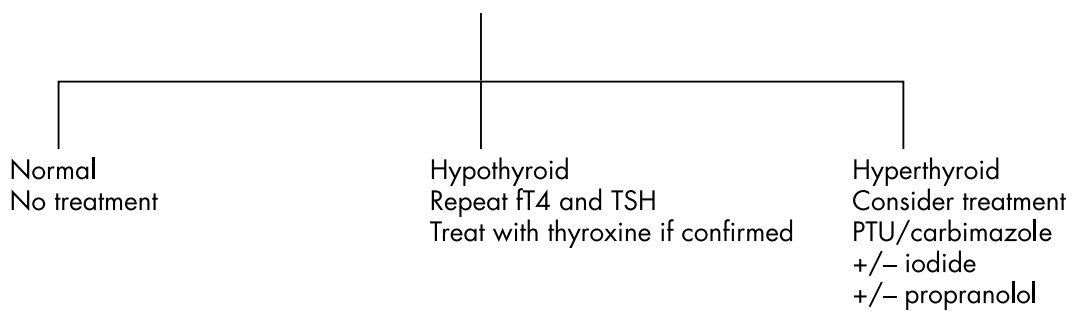

Figure 1 Investigation of babies of mothers with thyroid disease. TSH, Thyroid stimulating hormone; fT4, free thyroxine; TSI, thyroid stimulating immunoglobulin; PTU, propylthiouracil.

of thyrotoxicosis in babies of mothers with Graves' disease is usually required for four to eight weeks. In contrast, thyrotoxicosis secondary to activating mutations of the TSH receptor is persistent and may require ablative treatment usually with surgery. In view of the uncertain long term complications, neurodevelopmental follow up may be appropriate.

\section{SUMMARY}

In the preterm infant, hypothyroxinaemia is common. Although the degree of hypothyroxinaemia is associated with morbidity and mortality, it is unclear whether this is the cause or simply a reflection of illness severity. Supplementation with thyroid hormones is unlikely to influence tissue levels of T3, which are determined by specific deiodinase enzymes, and may even be detrimental.

Neonatal thyrotoxicosis is rare, but in babies born to mothers with a current or past history of Graves' disease is more likely to occur if there are high levels of maternal TSI, or thyrotoxicosis develops or requires treatment in pregnancy, or if the fetus is affected. Cord blood should be taken to assess thyroid function, and babies should be reviewed clinically and biochemically at 2 days (if the risk of thyrotoxicosis is high or unknown) and 1-2 weeks of postnatal age for evidence of thyrotoxicosis or hypothyroidism. Thyrotoxicosis should be treated with a thionamide, with or without iodide, or iodinecontaining contrast medium. Propranolol and corticosteroids should be considered in severe cases. The general practitioner should be informed and the parents warned about potential signs of thyrotoxicosis.

\section{REFERENCES}

1 DeZegher F, Pernasetti F, Vanhole C, et al. The prenatal role of thyroid hormone evidenced by fetomaternal Pit-1 deficiency. J Clin Endocrinol Metab 1995;80:3127-30

2 Cao X-Y, Jiang X-M, Dou Z-H, et al. Timing of vulnerability of the brain to iodine deficiency in endemic cretinism. N Engl J Med 1994;331:1739-44.

3 Valsma T, Gons MH, de Viilder JJ. Maternal-fetal transfer of thyroxine in congenital hypothyroidism due to a total organification defect or thyroid agenesis. New Engl J Med 1989;321:13-16.

4 Haddow JE, Palomaki GE, Allan WC, et al. Maternal thyroid deficiency during pregnancy and subsequent neuropsycological development of the child. N Engl J Med 1999;341:549-55. 
5 Richard K, Hume R, Kaptein E, et al. Ontogeny of iodothyronine deiodinases in human liver. J Clin Endocrinol Metab 1998;83:2868-74.

6 Fisher DA, Polk DH, Wu SY. Fetal thyroid metabolism: a pleuralistic system. Thyroid 1994;4:367-71

7 Burrow GN, Fisher DA, Larsen PR. Maternal and fetal thyroid function. N Engl J Med 1994:331:1072-8.

8 PolkDH, Reviczky A, Wu SY, et al. Metabolism of sulphoconjugated thyroid hormones in developing sheep. Am J Physiol 1994;266:E892-6. 9 Mol JA, Visser TJ. Rapid and selective inner ring deiodination of thyroxine sulfate by rat liver deiodinase. Endocrinology 1985;117:8-12.

10 Visser TJ. Role of sulfation in thyroid hormone metabolism. Clin Biol Interact 1994;92:293-303.

11 Ruiz de Ona C, Morreale de Escobar G, Calvo RM, et al. Thyrid hormone $5^{\prime}$-deiodinase in the rat fetus late in gestation: effects of maternal hypothyroidism. Endocrinology 1991;128:422-32.

12 van Wassenaer AG, Kok JH, Endert E, et al. Thyroxine administration to infants of less than 30 weeks' gestational age does not increase plasma triiodothyronine concentrations. Acta Endocrinol 1993;1 29:139-46.

13 Fisher DA. Thyroid function in premature infants. Clin Perinatol 1998;25:999-1014

14 Fuse Y, Shimizu M, Uga N, et al. Maturation of the feedback control of thyrotropin in premature infants. J Dev Physiol 1990;14:17-22.

15 Ares S, Escobar-Morreale HF, Quero J, et al. Neonatal hypothyroxinaemia: effects of iodine intake and premature birth. J Clin Endocrinol Metab 1997;82:1704-12.

16 Rooman RP, Du Caju MVL, Op De Beeck L, et al. Low thyroxinaemia occurs in the majority of very preterm newborns. Eur J Pediatr $1996 ; 155 ; 211-15$

17 Frank JE, Faix JE, Hermos RJ, et al. Thyroid function in very low birth weight infants: effects on neonatal hypothyroidism screening. J Pediatr 1996; 128:548-54

18 Van Wassenaer AG, Kok JH, Dekker FW, et al. Thyroid function in very preterm infants: influences of gestational age and disease. Pediatr Res 1997;42:812-18.

19 Mandel SJ, Hermos RJ, Larson CA, et al. Atypical hypothyroidism and the very low birthweight infant. Thyroid 2000;10:693-5.

20 Franklin RC, Purdie GL, O'Grady CM. Neonatal thyroid function: prematurity, prenatal steroids and respiratory distress syndrome. Arch Dis
Child 1986;61:589-92.

21 Weber G, Vigone MC, Rapa A, et al. Neonatal transient hypothyroidism: aetiological study. Italian Collaborative Study on Transient Hypothyroidism. Arch Dis Child Fetal Neonatal Ed 1998;79:F70-2.

22 Pavelka S, Kopecky P, Bendlova B, et al. Tissue metabolism and plasma levels of thyroid hormones in critically ill very premature infants. Pediatr Res 1997;42:604-9.

23 Reuss ML, Paneth N, Lorenz JM, et al. Correlates of low thyroxine values at newborn screening among infants born before 32 weeks gestation. Early Hum Dev 1997;28:821-7

24 Paul DA, Leef KH, Stefano J, et al. Low serum thyroxine on initial newborn screening is associated with intraventricular hemorrhage and death in very low birthweight infants. Pediatrics 1998;101:903-7.

25 Levington A, Paneth N, Reuss ML, et al. Hypothyroxinaemia of prematurity and risk of cerebral white matter damage. J Pediatr 1999:134:706-11.

26 Reuss ML, Paneth N, Pinto-Marin JA, et al. The relationship of transient hypothyroxinemia in preterm infants to neurologic development at two years of age. N Engl J Med 1996;28:821-7

27 Den Ouden AL, Kok JH, Verkerk P, et al. The relation between neonata thyroxine levels and neurodevelopmental outcome at 5 and 9 years in a notional cohort of very preterm and/or very low bith weight infants. Pediatr Res 1996:39:142-5.

28 Meijer WJ, Verloove-Vanhorick SP, Brand R, et al. Transient hypothyroxinaemia associated with developmental delay in very preterm infants. Arch Dis Child 1992:67:944-7.

29 Lucas A, Rennie J, Baker BA, et al. Low plasma triiodothyronine concentrations and outcome in preterm infants. Arch Dis Child 1988;63:1201-6.

30 Lucas A, Morley R, Fewtrell MS. Low triiodothyronine concentration in preterm infants and subsequent intelligence quotient (IQ) at 8 year follow up. BM 1996:312:1132-3.

31 Osborn DA. Thyroid hormone for preventing of neurodevelopmental impairment in preterm infants. Cochrane Database Syst Rev 2000;2:CD001070.

32 Chowdhry P, Scanlon JW, Auerbach R, et al. Results of controlled double-blind study of thyroid replacement in very low birth weight premature infants with hypothyroxinaemia. Pediatrics 1984;73:301-5.

33 Amato M, Pasquier S, Carasso A, et al. Postnatal thyroxine administration for idiopathic respiratory distress syndrome in preterm infants. Horm Res 1988;29:301-5.

34 Vanhole C, Aerssens P, Naulaers G, et al. L-thyroxine treatment of preterm newborns: clinical and endocrine effects. Pediatr Res 1997; 42:87-92

35 Van WassenaerAG, Kok JH, de Vijlder JJ, Briet JM, et al. Effects of thyroxine supplementation on neurologic development in infants born at less than 30 weeks' gestation. N Engl J Med 1997;42:87-92.

36 Crowther CA, Hiller JE, Haslam RR, et al. Australian collaborative trial of antenatal thyrotopin-releasing hormone: adverse effects at 12 month follow-up. Pediatrics 1997;99:311-17.

37 Rapaport R, Rose SR, Freemark M. Hypothroxinaemia in the preterm infant: the benefits and risks of thyroxine treatment. J Pediatr $2001 ; 139$ : 182-8.
38 Hoffman WH, Sahasrananan P, Ferandos SS, et al. Tranient thyrotoxicosis in an infant delivered to a long-acting stimulator (LATS)and LATS protector-negative, thyroid stimulating antibody-positive woman with Hashimoto's thyroiditis. J Clin Endocrinol Metab 1982;54:354-6.

39 Schwab KO, Gerlich M, Broecker M, et al. Constitutively active germline mutation of the thyrotropin receptor gene as a cause of congenital hyperthyroidism. J Pediatr 1997;131:899-904.

40 de Roux N, Polak M, Couet J, et al. A neomutation of the thyroid-stimulating hormone receptor in a severe neonatal hyperthyroidism. J Clin Endocrinol Metab 1996;81:2023-6.

41 Yoshimoto $M$, Nakayama $M$, Baba $T$, et al. A case of neonatal McCune-Albright syndrome with Cushing syndrome and hyperthyroidism. Acta Paediatr Scand 1991;80:984-7.

42 Spiegel AM. The molecular basis of disorders caused by defects in $G$ proteins. Horm Res 1997;47:89-96.

43 Wing DA, Millar LK, Koonings PP, et al. A comparison of propylthiouracil versus methimazole in the treatment of hyperthyroidism in pregnancy. Am J Obstet Gynecol 1994;170:90-5.

44 Kamijo K, Saito T, Saito M, et al. Transient subclinical hyperthyroidism in early pregnancy. Endocrinol Jpn 1990;37:397-403.

45 Fisher DA. The thyroid. In: Kaplan SA, ed. Clinical pediatric endocrinology. Philadelphia: WB Saunders, 1990:114-15.

46 Tamaki H, Amino N, Aoza M, et al. Universal predictive criteria for neonatal overt thyrotoxicosis requiring treatment. Am J Perinatol 1988;5:152-8

47 Mortimer RH, Tyack SA, Galligan DA, et al. Graves' disease in pregnancy: TSH receptor binding inhibiting immunoglobulins and maternal and neonatal thyroid function. Clin Endocrino 1990;32:141-52.

48 Ramsay I. Fetal and neonatal hyperthyroidism. Contemp Rev Obstet Gynaecol 1991;3:74-8.

49 Munro DS, Dirmikis SM, Humphries $H$, et al. The role of thyroid stimulating immunoglobulins of Graves's disease in neonatal thyrotoxicosis. BrJ Obstet Gynaecol 1978;85:837-43.

50 Samuel S, Pildes RS, Lewison $M$, et al. Neonatal hyperthyroidism in an infant born of an euthyroid mother. American Journal of Disease in Children 1971;121:440-3.

51 Hollingsworth DH, Mabry CC. Congenital Graves' disease: four familial cases with long-term follow-up and perspective. American Journa of Disease in Children 1976;130:148-55.

52 Mestman JH. Hyperthyroidism in pregnancy. Clin Obstet Gynecol 1997;40:45-64.

53 Millar LK, Wing DA, Leung AS, et al. Low birth weight and preeclampsia in pregnancies complicated by hyperthyroidism. Obstet Gynecol 1994;84:946-9.

54 Watson WJ, Fiegen MM. Fetal thyrotoxicosis associated with nonimmune hydrops. Am J Obstet Gynecol 1995;172:1039-40.

55 Davis LE, Lucas M, Hankins GDV, et al. Thyrotoxicosis complicating pregnancy. Am J Obstet Gynecol 1989;160:63-70.

56 Zakariia M, McKenzie JM, Munro DS. Immunoglobulin G inhibitor of thyroid-stimulating antibody is a cause of delay in the onset of neonatal Graves' disease. J Clin Invest 1983:72:1352-6.

57 Zakarija M, McKenzie JM, Hoffman WH. Prediction and therapy of intrauterine and late-onset neonatal hyperthyroidism. J Clin Endocrino Metab 1986;62:368-71.

$58 \mathrm{O}^{\prime}$ Hearlihy $\mathbf{C}$. Neonatal thyrotoxicosis with long acting thyroid stimulator-protector. Ir Med J 1977;70:124-5.

59 Skuza KA, Sills IN, Stene M, et al. Prediction of neonatal hyperthyroidism in infants born to mothers with Graves' disease. J Pediatr 1996; 128:264-7.

60 Zakarija M, McKenzie M. Pregnancy-associated changes in the thyroid stimulating antibody of Graves' disease and the relationship to neonatal hyperthyroidism. J Clin Endocrinol Metab 1983;57:1036-40

61 Sunshine P, Kusumoto H, Kriss JP. Survival time of circulating long-acting thyroid stimulator in neonatal thyrotoxicosis: implications for diagnosis and therapy of the disorder. Pediatrics 1965:36:869-76.

62 Connors MH, Styne DM. Transient neonatal 'athyrosis' resulting from thyrotropin-binding inhibitory immunoglobulins. Pediatrics 1986;78:287-90.

63 Matsuura N, Konishi J, Fujieda K et al. TSH-receptor antibodies in mothers with Graves' disease and outcome in their offspring. Lance 1988;i:14-17.

64 Tamaki H, Amino N, Takeoka K, et al. Prediction of later development of thyrotoxicosis or central hypothyroidism from the cord serum thyroid-stimulating hormone level in neonates born to mothers with Graves' disease. J Pediatr 1989:115:318-21.

65 Mandel SH, Hanna C, LaFranchi S. Thyroid function of infants born to mothers with Graves' disease. J Pediatr 1990;117:169-70

66 Momotani N, Ito K, Hamada N, et al. Maternal hyperthytroidism and congenital malformation in the offspring. Clin Endocrinol 1984;20:695-700

67 Khoury JM, Becerra JE, d'Almada PJ. Maternal thyroid disease and risk of birth defects in offspring: a population based case controlled study. Paediatr Perinatol Epidemiol 1989;3:402-20.

68 Mitsuda N, Tamaki H, Amino N, et al. Risk factors for developmental disorders in infants born to women with Graves' disease. Obstet Gynecol 1992;80:359-64

69 Jansson R, Dahlberg PA, Lindstrom B. Comparative bioavailability of carbimazole and methimazole. Int J Clin Pharmacol Ther Toxicol 1983;21:505-10.

70 Mujtaba Q, Burrow GN. Treatment of hyperthyroidism in pregnancy with propylthiouracil and methimazole. Obstet Gynecol 1975;46:282-6. 
71 Kalb RE, Grossman ME. The association of aplasia cutis congenita with therapy of maternal thyroid disease. Pediatr Dermatol 1986;3:327-30.

72 Mandel SJ, Brent GA, Larsen PR. Review of antithyroid drug therapy during pregnancy and report of a case of aplasia cutis. Thyroid 1994:4:129-33.

73 Burrow GN, Bartsocas C, Klatskin EH, et al. Children exposed in utero to propylthiouracil: subsequent intellectual and physical development. American Journal of Disease in Children 1968;1 16:161-5.

74 McCarroll AM, Hutchinson M, McAuley R, et al. Long-term assessment of children exposed in utero to carbimazole. Arch Dis Child 1976;51:532-6.

75 Eisenstein Z, Weiss $M$, Katz $Y$, et al. Intellectual capacity of subjects exposed to methimazole or propylthiouracil in utero. Eur J Pediatr 1992;151:558-9.

76 Messer PM, Hauffa BP, Olbricht T, et al. Antithyroid drug treatment of Graves' disease in pregnancy: long-term effects on somatic growth, intellectual development and thyroid function of the offspring. Acta Endocrinol 1990;123:311-16.

77 Daneman D, Howard NJ. Neonatal thyrotoxicosis: intellectual impairment and craniosynostosis in later years. J Pediatr 1980;97:257-9.

78 Lamberg B-A, Ikonen E, Osterlund K, et al. Antithyroid treatment of maternal hyperthyroidism during lactation. Clin Endocrinol 1984:21:81-7.
79 Azizi F. Effect of methimazole treatment of maternal thyrotoxicosis on thyroid function in breast-feeding infants. J Pediatr 1996;1 28:855-8.

80 Kampmann JP, Johansen K, Hansen JM, et al. Propylthiouracil in human milk. Revision of a dogma. Lancet 1980;8171:736-7.

81 Low LCK, Lang J, Alexander WD. Excretion of Carbimazole and propylthiouracil in breast milk. Lancet 1979;ii:1011.

82 Tegler L, Lindstrom B. Antithroid drugs in milk. Lancet 1980;ii:571.

83 Geffner DL, Azukizawa M, Hershman J. Propylthiouracil blocks extrathyroidal conversion of throxine to triiodothironine and augments thyrotropin secretion in man. J Clin Invest 1975;55:224-9.

84 Karpman B, Rapoport B, Filetti S, et al. Treatment of neonatal hyperthyroidism due to Graves' disease with sodium ipodate. J Clin Endocrinol Metab 1987;64:1 19-23.

85 Transue D, Chan J, Kaplan M. Management of neonatal Graves' disease with iopanoic acid. J Pediatr 1992;121:472-4.

86 Munro DS, Cooke ID, Dirmikis SM, et al. Neonatal thyrotoxicosis. QJM 1976;45:689-90.

87 Tamaki H, Amino N, Miyai K, et al. Effect of exchange transfusion on serum throtropin-receptor antibody and development of neonatal thyrotoxicosis. J Pediatr Endocrinol 1991:4:205-8.

88 Wit JM, Gerards L, Vermeulen-Meiners C, et al. Neonatal thyrotoxicosis treated with exchange transfusion and Lugol's iodine. Eur J Pediatr $1985 ; 143: 317-19$

\section{Archimedes}

In order to give the best care to patients and families, paediatricians need to integrate the highest quality scientific evidence with clinical expertise and the opinions of the family. Archimedes is a bimonthly section in Archives which seeks to assist practising clinicians by providing "evidence based" answers to common questions which are not at the forefront of research but are at the core of practice.

The format of Archimedes may be familiar. A description of the clinical setting is followed by a structured clinical question and a brief report of the search. The best evidence available to answer the question is provided as a summary table (which is electronically linked to more detailed appraisals). To pull the information together, a commentary follows. Finally, to make it all much more accessible, a box provides the clinical bottom line. This month the following topics have been published which may be of interest to neonatologists:

- Are topical corticosteroids superior to systemic histamine antagonists in treatment of allergic seasonal rhinitis?

- Do behavioural treatments for sleep disorders in children with Down's syndrome work?

- Inhaled steroids in the treatment of mild to moderate persistent asthma in children: once or twice daily administration?

Previous Archimedes questions can be found in the issues of Archives published in the Fetal and Neonatal edition months since September 2001. Readers wishing to submit their own questions - with best evidence answers-are encouraged to read the Instructions for Authors at http://www.archdischild.com. 